\title{
Effects of Dermatopontin gene silencing on apoptosis and proliferation of osteosarcoma MG-63 cells
}

\author{
LI-CHENG XI ${ }^{1}$, YUN-XI JI ${ }^{2}$, DONG YIN ${ }^{1}$, ZI-XING ZHAO ${ }^{1}$, SI-CHENG HUANG ${ }^{1}$, \\ SHAO-LIN YU ${ }^{3}$, BO-YU LIU ${ }^{4}$ and HONG-YU LI ${ }^{1}$ \\ ${ }^{1}$ Department of Orthopedics, The People's Hospital of Guangxi Zhuang Autonomous Region, Nanning, \\ Guangxi 530021; ${ }^{2}$ Department of Orthopedics, Zhejiang Provincial Hospital of TCM, Hangzhou, \\ Zhejiang 310000; ${ }^{3}$ Department of Orthopedics, Ji'an Central Hospital, Ji'an, Jiangxi 343000; \\ ${ }^{4}$ Department of Orthopedics, Liuzhou Work's Hospital, Liuzhou, Guangxi 530021, P.R. China
}

Received March 28, 2017; Accepted September 19, 2017

DOI: $10.3892 / \mathrm{mmr} .2017 .7866$

\begin{abstract}
The present study aimed to investigate the effect of Dermatopontin (DPT) gene silencing on the apoptosis and proliferation of osteosarcoma MG-63 cells. Three eukaryotic expression vectors of short hairpin (sh)RNA fragments targeting different loci of DPT were designed and transfected into an osteosarcoma cell line MG-63. The cells were assigned to a blank, shRNA-control, DPT-shRNA-a, DPT-shRNA-b or DPT-shRNA-c group. The shRNA with the highest silencing efficiency was screened using reverse transcription-quantitative polymerase chain reaction and western blotting. The screened shRNA was transfected into MG-63 cells. The proliferation, cell cycle and apoptosis of MG-63 cells were measured using a Cell Counting Kit-8 assay, flow cytometry and Annexin V-fluorescein isothiocyanate assay. The recombinant plasmids containing DPT shRNA were successfully constructed. DPT gene silencing was able to significantly reduce the proliferation rate of MG-63 cells $(\mathrm{P}<0.05)$. The proportion of cells in the $\mathrm{G}_{0} / \mathrm{G}_{1}$ phase and in the $\mathrm{G}_{2} / \mathrm{M}$ phase increased significantly (both $\mathrm{P}<0.05)$, while the proportion of cells in the $\mathrm{S}$ phase decreased $(\mathrm{P}<0.05)$. Furthermore, the cell apoptosis rate increased significantly $(\mathrm{P}<0.05)$. These results demonstrate that $D P T$ gene silencing is able to reduce the proliferation of MG-63 cells, slow down cell cycle progression and promote apoptosis, hence may become a novel target for the treatment of osteosarcoma.
\end{abstract}

\section{Introduction}

Osteosarcoma is a relatively common primary bone malignancy and tends to occur in young people (1). The incidences of osteosarcoma in children and adolescents are high and

Correspondence to: Dr Hong-Yu Li, Department of Orthopedics, The People's Hospital of Guangxi Zhuang Autonomous Region, 6 Taoyuan Road, Nanning, Guangxi 530021, P.R. China

E-mail: 469459442@qq.com

Key words: Dermatopontin, osteosarcoma, MG-63, cell proliferation, cell cycle, cell apoptosis, gene silencing accounts for approximately $20 \%$ of all primary bone cancers; the incidence of osteosarcoma is around 0.2-3/100,000 per year, which is even higher in the age group of 15-19 years (0.8-11/100,000 per year) (2). Despite the fact that several improvements have been made in the curative protocols, osteosarcoma remains a devastating disease with poor early diagnosis as well as a low long-term survival rate (3), and the 5 -year survival rate obtained by traditional chemotherapy in combination with surgical resection is still below $70 \%$ (4), mainly due to the resistance to chemotherapy and resulting failure of osteosarcoma treatment (5). Therefore, a deeper understanding of osteosarcoma development on the molecular level may pave the way for future therapy development. In addition, the process of tumorigenesis, i.e., a cumulative occurrence of gene mutations that influence the expression of both oncogenes and tumor suppressor genes, may also affect osteosarcoma development, where the osteoprogenitor cells acquire the ability of uncontrolled proliferation and bone formation (6). Therefore, using genome-wide sequencing, many studies have been carried out to identify genes responsible for the development of osteosarcoma (7-9).

Dermatopontin $(D P T)$, initially found by purification of dercoin in calf skin, is an extracellular matrix (ECM) protein with a tyrosine residue and a molecular weight of $22 \mathrm{kDa}$, and can promote cell adhesion and ECM assembly by closely interacting with other ECM proteins (10). Since ECM degradation is an important prerequisite for tumor metastasis $(11,12), D P T$ can affect tumor prognosis by regulating tumor invasion and metastasis $(13,14)$. The expression of DPT is decreased in systemic sclerosis and hypertrophic scaring (15) as well as uterine leiomyomas and keloids (16) and may play an important role in wound healing (17). Recently, it has been shown that DPT can mediate in vivo prostate cell growth (18) and inhibit the metastasis of human oral cancer (13). Unfortunately, the DPT expression in osteosarcoma and its functional characteristics have not yet been thoroughly studied. Therefore, in this paper, we will analyze the effect of DPT during apoptosis and proliferation of osteosarcoma MG-63 cells, thus providing a potential therapeutic target and new ideas for chemotherapy and gene therapy of osteosarcoma. 


\section{Materials and methods}

Cell culture and treatment. The osteosarcoma MG-63 cells were purchased from Shanghai Cell Bank of Chinese Academy of Sciences (Shanghai, China). The cells were cultured in 1640 media supplemented with $10 \%$ inactivated fetal calf serum plus 100 units $/ \mathrm{ml}$ penicillin and $100 \mathrm{mg} / \mathrm{ml}$ streptomycin (all from Gibco, Thermo Fisher, Waltham, MA, USA) at $37^{\circ} \mathrm{C}$ and $5 \% \mathrm{CO}_{2}$. When the cells grew to $80 \%$ confluency, they were digested using $0.25 \%$ trypsin and passaged.

Establishment of DPT gene silencing model. According to the design principle of shRNA, the sequence of the DPT gene was obtained from GenBank (NM_001937.4), and RNA interference sites provided by Invitrogen on-line (Thermo Fisher) were used to design 3 interference sequences, i.e., shRNA-a, shRNA-b and shRNA-c. Blast software was used for comparison on the human genome, and the sequence of $D P T$ gene was identified as unique. In the same way, a non-specific shRNA-control was designed as a negative sequence without any matching sequences in the human genome. Four shRNA sequences were synthesized by Sangon (Shanghai, China): ShRNA-control: 5'-ACTACC GTT GTTATAGGTG-3'; DPT-shRNA-a: 5'-TGGCGGGAAGTGTGA AGCG-3'; DPT-shRNA-b: 5'-CATCAACGAGTGCTCCAGC-3'; DPT-shRNA-c: 5'-GGTGTCTTCCAGATCCTGA-3'. BamHI and HindIII restriction enzyme cutting sites (TaKaRa Bio, Tokyo, Japan) were added to both ends of the sequences, and each designed oligonucleotide sequence was inserted into a pSIREN-RetroQ-TetH vector (TaKaRa Bio). The recombinant plasmids were amplified by Escherichia coli (E. coli) DH5a (Tiangen, Beijing, China) and cultured overnight in LB medium containing Ampicilin. The plasmids were extracted using a plasmid miniprep kit (Beyotime, Shanghai, China) and were sequenced by Invitrogen (Invitrogen, Thermo Fisher, Waltham, MA, USA) to check whether the base sequences of the shRNA fragments were correct.

Cell grouping and transfection. In the experiment, the cells were assigned to blank group, shRNA-control group, DPT-shRNA-a group, DPT-shRNA-b group and DPT-shRNA-c group. The blank group received no treatment. The shRNA-control group was transfected with shRNA-control plasmids. DPT-shRNA-a, DPT-shRNA-b and DPT-shRNA-c groups were transfected with DPT-shRNA-a, DPT-shRNA-b and DPT-shRNA-c plasmids, respectively. According to the instructions of Fugene transfection reagent (Invitrogen, Thermo Fisher), the MG-63 cells were seeded on 6-well plates the day prior to cell transfection and routinely incubated. The culture media were changed at $2 \mathrm{~h}$ before the transfection, followed by adding $2 \mathrm{ml}$ of 1640 culture media into each well. For each well, $8 \mu 1$ Fugene reagent and $3.2 \mu \mathrm{g}$ of plasmids were mixed and incubated for $20 \mathrm{~min}$ at room temperature. The 1640 culture media in each well were aspirated and $200 \mu 1$ of Opti-MEN media were added into each well, followed by $800 \mu 1$ of Fugene/plasmid mixture. The plates were incubated at $37^{\circ} \mathrm{C}$ for $5 \mathrm{~h}$. After the transfection, $2 \mathrm{ml}$ of 1640 media were added into each well and the plates were incubated at $37^{\circ} \mathrm{C}$. After $24,36,48$ and $72 \mathrm{~h}$, the transfection efficiency was observed by fluorescence microscopy.
Table I. Effects of DPT gene silencing on cell cycle of osteosarcoma MG-63 cells, as determined by flow cytometry.

\begin{tabular}{lccc}
\hline Group & $\mathrm{G} 0 / \mathrm{G} 1$ & $\mathrm{~S}$ & $\mathrm{G} 2 / \mathrm{M}$ \\
\hline Blank & $61.8 \pm 3.1$ & $26.3 \pm 0.7$ & $11.9 \pm 3.6$ \\
shRNA-Control & $62.3 \pm 1.0$ & $26.8 \pm 0.5$ & $10.9 \pm 1.5$ \\
DPT-shRNA-a & $68.7 \pm 3.8^{\mathrm{a}}$ & $14.2 \pm 0.2^{\mathrm{a}}$ & $17.1 \pm 3.9^{\mathrm{a}}$ \\
\hline
\end{tabular}

${ }^{a} \mathrm{P}<0.05$ compared with the blank group. shRNA, short hairpin RNA.

Quantitative real time polymerase chain reaction ( $q R T-P C R)$. After $36 \mathrm{~h}$ of transient shRNA transfection, the cells were collected in a $15 \mathrm{ml}$ centrifuge tube and the total RNA of osteosarcoma MG-63 cells was extracted according to the instruction of a RNA extraction kit (Promega Corp., Madison, WI, USA). The optic density (OD) 260/280 ratio of the extracted RNA samples was analyzed by an ultraviolet spectrophotometer, and the RNA concentration was calculated. The RNA samples were then stored at $-80^{\circ} \mathrm{C}$ for future use. PCR primers were designed using the Primer6.0 primer design software, according to the gene sequences in the Genebank database: $\beta$-actin: Forward (5'-3') TGGCATTGCCGACAG GATGCAGCAA; reverse (5'-3') CTCCTCATACTCCTG CTTGCTGAT; DPT: Forward (5'-3') GGTGGCTACGGG TACCCATA; reverse (5'-3') GTCAGAGCCTTCCTTCTTGC. The primers were synthesized by Sangon (Shanghai, China). Reverse transcription (RT) was performed according to the protocol provided with the RNA Reverse Transcription Kit (Promega Corp.). PCR was carried out in a two-step reaction: Pre-denaturation at $95^{\circ} \mathrm{Cfor} 15 \mathrm{~min}$, followed by 40 cycles of denaturation at $95^{\circ} \mathrm{Cfor} 10 \mathrm{sec}$ and annealing/extension at $60^{\circ} \mathrm{C}$ for $30 \mathrm{sec}$. The qRT-PCR reaction system consisted of $12.5 \mu 1$ of SYBR Green Mix, $1 \mu 1$ of forward primer, $1 \mu 1$ of reverse primer, $2 \mu \mathrm{l}$ of DNA template, and $8.5 \mu \mathrm{l}$ of $\mathrm{ddH}_{2} \mathrm{O}$ (Promega Corp.). $\beta$-actin was used as an internal reference. The reliability of the PCR was evaluated by the dissolution curve and the cycle quantification $(\mathrm{Cq})$ value was obtained. The relative expression of the target gene was calculated according to $2^{-\Delta \Lambda} \mathrm{Cq}$, and each measurement was repeated three times.

Western blot analysis. The protein in each cell group was extracted at $36 \mathrm{~h}$ after transient shRNA transfection. The protein concentration was determined by according to the manual of a BCA kit (Boster, Wuhan, Hubei, China). The extracted protein was added to the loading buffer and then boiled at $95^{\circ} \mathrm{C}$ for $5 \mathrm{~min}$. A total of $30 \mu \mathrm{g}$ samples were added into each well of a $10 \%$ polyacrylamide gel (Boster, Wuhan, Hubei, China), and the protein was then separated by electrophoresis. The electrophoresis voltage was $80 \mathrm{~V}$ changed to $120 \mathrm{~V}$ with wet transfer. The membrane transfer voltage was $100 \mathrm{mV}$, and the duration was 45-70 min. After transfer using a polyvinylidene fluoride (PVDF) membrane, the membrane was mounted in $5 \%$ bovine serum albumin (BSA) for $1 \mathrm{~h}$ at room temperature, followed by addition of primary anti-DPT (1:1,000, Abcam, Cambridge, UK) antibody and incubation at $4^{\circ} \mathrm{C}$ overnight. TBST solution was used to rinse the membrane ( 3 times of $5 \mathrm{~min}$ each), and the membrane 
A

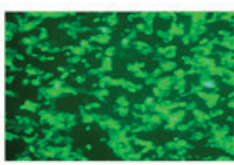

$24 \mathrm{~h}$

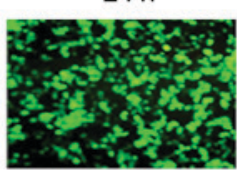

$48 \mathrm{~h}$

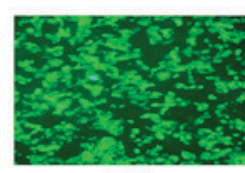

$36 \mathrm{~h}$

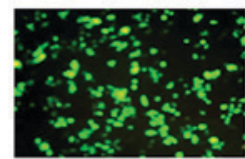

$72 \mathrm{~h}$

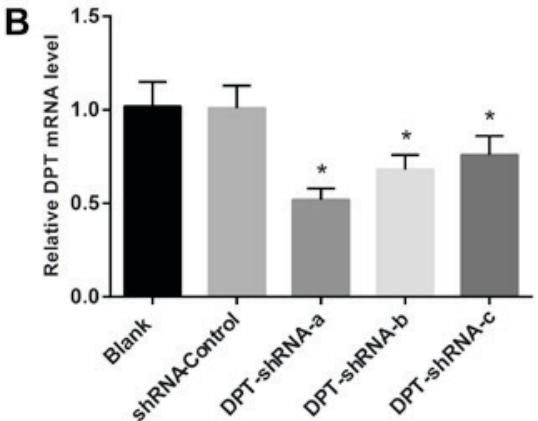

C

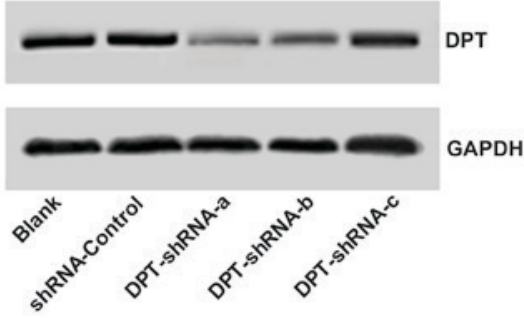

Figure 1. Comparisons of changes of DPT expression in MG-63 cells transfected with DPT-shRNA plasmids. (A) transfection efficiency in MG-63 cells transfected with DPT-shRNA plasmids; (B), the expression of DPT mRNA in MG-63 cells at $36 \mathrm{~h}$ after transfection with DPT-shRNA plasmid; (C), The expression of $D P T$ protein in MG-63 cells at $36 \mathrm{~h}$ after transfection with DPT-shRNA plasmid; (D), the grey values of DPT protein in different groups of MG-63 cells were measured. * $\mathrm{P}<0.05$ compared with the blank group and the shRNA-control group; DPT, Dermatopontin.

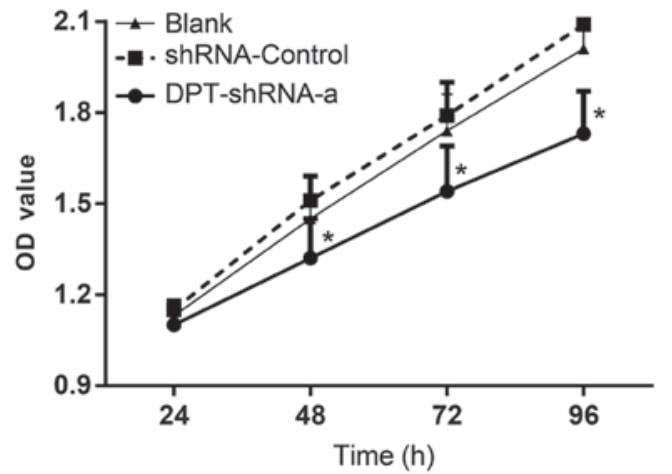

Figure 2. The inhibitory effect of $D P T$ gene silencing on the proliferation of osteosarcoma MG-63 cells. * $\mathrm{P}<0.05$ compared with the blank group and the shRNA-control group; DPT, Dermatopontin.

was incubated with the corresponding secondary antibodies at room temperature for $1 \mathrm{~h}$. After additional membrane washing (3 times of $5 \mathrm{~min}$ each), chemiluminescence reagent was added and the membrane was developed. $\beta$-actin was used as the internal reference (1:5,000, Kangchen, Shanghai, China). Each measurement was repeated 3 times. A Bio-rad Gel DOC EZ imager (Bio-Rad, Hercules, CA, USA) was used to image the membrane. The gray value analysis of the target band was conducted using the Image $\mathbf{J}$ software.

Cell Counting Kit-8 (CCK-8) assay. After the normal MG-63 cells and the cells transfected with DPT-shRNA-a and shRNA-control reached the phase of logarithmic growth, they were collected and seeded into 96-well plates at a concentration of $10^{3}$ cells/well. In each well, $200 \mu$ l of cell culture media were added. Three duplicated wells were set up for each cell group, and the experiment was repeated 3 times. After culturing for $24,48,72$, and $96 \mathrm{~h}, 20 \mu \mathrm{l}$ of CCK-8 reagent were added into each well of the 96-well plates, which were returned to an incubator for cell culture. Subsequently, the cells were removed from the incubator $4 \mathrm{~h}$ later and the absorbance (A) value at $490 \mathrm{~nm}$ was measured with a microplate reader. The cell growth curve was plotted using time as the $\mathrm{X}$-axis and the value of A490 nm as the Y-axis.

Flow cytometry. Cells were harvested after $36 \mathrm{~h}$ of transfection and washed once with $1 \mathrm{x}$ PBS, and then resuspended in PBS containing $75 \%$ ethanol and $0.5 \mathrm{mmol} / 1$ LEDTA. After fixing for $1 \mathrm{~h}$ at $4^{\circ} \mathrm{C}$, the cells were centrifuged at $2000 \mathrm{rpm}$ for $5 \mathrm{~min}$, and the supernatant was discarded. The cells were washed once with 1x PBS and resuspended in $500 \mu \mathrm{l}$ of PBS containing $0.1 \%$ Triton X-100 and $50 \mu \mathrm{g} / \mathrm{ml}$ RNase, and $90 \mu 1$ of $0.5 \mathrm{mg} / \mathrm{ml}$ propidium iodide (PI) were added into the suspension rapidly. The suspension was then mixed well using a pipette, and placed in the dark for $30 \mathrm{~min}$ of reaction at room temperature. The solution was then filtered with a nylon membrane and analyzed by an EPICS XL-4 flow cytometer (Beckman Coulter, Brea, CA, USA). Each measurement was repeated 3 times.

Annexin V-FITC was used to detect apoptosis. After $36 \mathrm{~h}$ of transfection, the cells were taken out from the incubator, washed twice with PBS, digested with $0.25 \%$ trypsin and collected by centrifugation at $1,000 \mathrm{rpm}$ for $10 \mathrm{~min}$. The cells were then washed 3 times with PBS and resuspended. The number of cells was counted and the cell concentration was adjusted to $5 \times 10^{5}$ cells $/ \mathrm{ml}$. A volume of $5 \mu \mathrm{l}$ Annexin V-FITC 

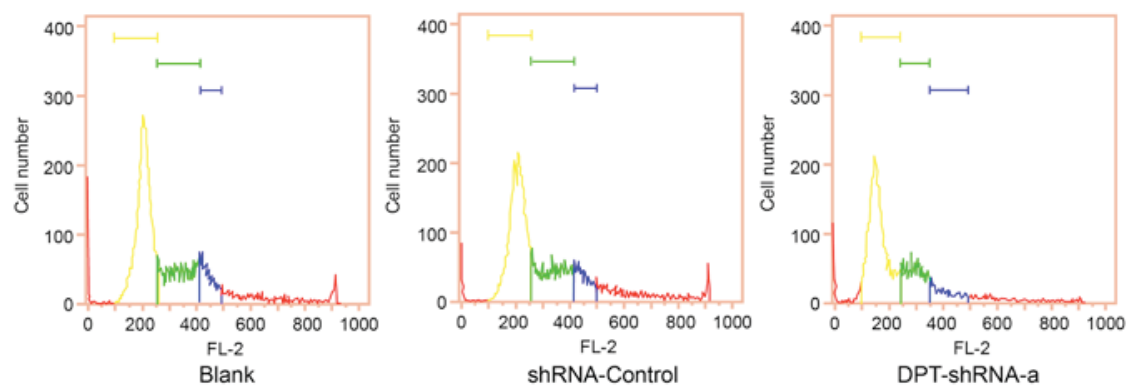

Figure 3. Effects of DPT gene silencing on cell cycle of osteosarcoma MG-63 cells, as determined by flow cytometry. DPT, Dermatopontin.

A
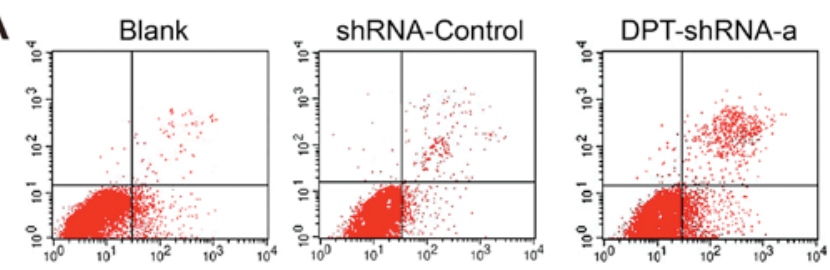

B

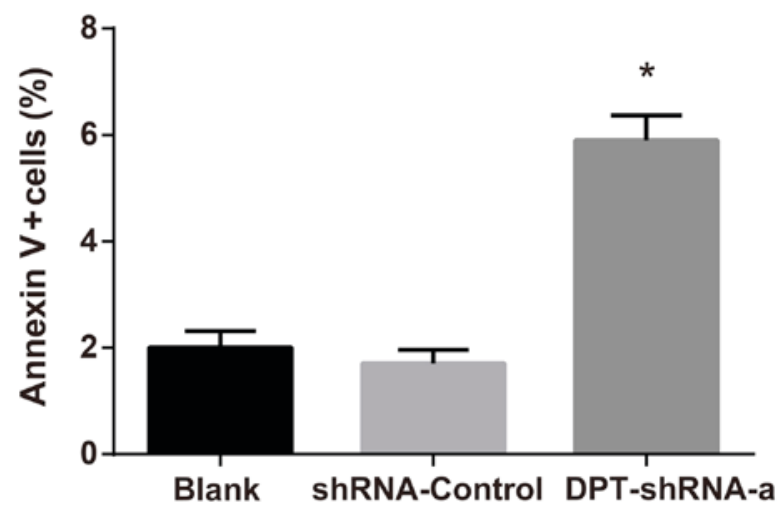

Figure 4. Effects of DPT gene silencing on apoptosis of osteosarcoma MG-63 cells. (A) The flow cytometry analysis; (B) the comparison of apoptotic rate. ${ }^{*} \mathrm{P}<0.05$ compared with the blank group and the shRNA-control group; DPT, Dermatopontin.

was added into $100 \mu \mathrm{l}$ cells, gently mixed, and incubated in the dark at room temperature for $10 \mathrm{~min}$. The suspension was then centrifuged at $1000 \mathrm{rpm}$ for $5 \mathrm{~min}$ and the supernatant was discarded. A volume of $10 \mu \mathrm{l}$ PI staining solution was added and gently mixed before analyzing the cells by flow cytometry. The percentage of Annexin V+/PI- cells in the total cell number was used as the apoptosis rate, and each measurement was repeated 3 times.

Statistical analysis. The data were analyzed by SPSS20.0 statistical software. The measurement data were expressed as mean \pm standard deviation (SD). The differences among multiple groups were analyzed by analysis of variance (ANOVA). The difference between two groups was verified using t test. A $\mathrm{P}$-value of $<0.05$ was considered statistically significant.

\section{Results}

DPT gene silencing in osteosarcoma MG-63 cells. After transfection with DPT-shRNA, the percentage of MG-63 cells with green fluorescence was 91,97, 92 and 87\%, respectively, at $24,36,48$ and $72 \mathrm{~h}$ post transfection. At $36 \mathrm{~h}$ after transfection, the proportion of green fluorescent cells reached the highest level (Fig. 1A). The expression of DPT was detected by qRT-PCR. The results showed that the expression of DPT in DPT-shRNA-transfected cells was significantly lower than that in the shRNA-control group $(\mathrm{P}<0.05)$, while the expression of DPT in the shRNA-control group was similar to that in the blank group $(\mathrm{P}>0.05)$. This indicates that the DPT-shRNA recombinant plasmids can significantly inhibit the expression of DPT gene, whose expression was the lowest in the DPT-shRNA-a group (Fig. 1B). Western blotting showed that the expression of $D P T$ protein in cells transfected with DPT-shRNA-a, b and c was significantly attenuated compared to that in the shRNA-control group (all $\mathrm{P}<0.05$ ), especially for the DPT-shRNA-a group. There was no significant difference between the DPT-shRNA-c group and the blank group (Figs. 1C and 1D). Therefore, DPT-shRNA-a recombinant plasmid was selected for subsequent experiments.

Effects of DPT gene silencing on the proliferation of MG-63 cells. MG-63 cells were transfected with DPT-shRNA-a plasmid and the cell proliferation was detected by the CCK-8 assay. The OD values of cells in the blank group were $1.13 \pm 0.04,1.45 \pm 0.07,1.74 \pm 0.12$ and $2.01 \pm 0.18$, respectively, at $24,48,72$ and $96 \mathrm{~h}$ post transfection. The OD values of cells in the shRNA-control group were $1.15 \pm 0.03,1.51 \pm 0.08,1.79 \pm 0.11$ and 2.09 \pm 0.17 , respectively, at 24, 48, 72 and $96 \mathrm{~h}$ post transfection. The OD values of cells in the DPT-shRNA-a group were $1.10 \pm 0.05,1.32 \pm 0.13,1.54 \pm 0.15$ and $1.73 \pm 0.14$, respectively, at $24,48,72$ and $96 \mathrm{~h}$ post transfection. There were significant differences between cells in the DPT-shRNA-a group and cells in the shRNA-control, the blank groups at 48, 72 and $96 \mathrm{~h}$ (all $\mathrm{P}<0.05$ ), while the OD values in the shRNA-control and blank groups were not significantly different ( $\mathrm{P}>0.05)$ (Fig. 2). These results showed that $D P T$ silencing could significantly inhibit the proliferation of MG-63 cells.

Effects of DPT gene silencing on cell cycle of MG-63 cells. Flow cytometry analysis showed that the proportion of cells at G0/G1 and G2/M phases in the DPT-shRNA-a group was significantly higher than that in the blank group (both $\mathrm{P}<0.05$ ), while the proportion of cells at S phase in the DPT-shRNA-a group was significantly lower than that in the blank group $(\mathrm{P}<0.05)$, indicating that DNA replication in DPT-shRNA-a cells decreased and their cell cycle progression was slowed down. In addition, there was no significant difference between 
the shRNA-control group and the blank group $(\mathrm{P}>0.05)$ (Fig. 3, Table I).

Effects of DPT gene silencing on apoptosis of MG-63 cells. After double staining with Annexin V and PI, flow cytometry measurement was carried out to detect the percentage of Annexin V+/PI- cells, which was used as the apoptotic rate and was compared among different groups. The results revealed that the apoptotic rate in the DPT-shRNA-a group was significantly higher than that in the blank group and the shRNA-control group (both $\mathrm{P}<0.05$ ), but there was no significant difference between the shRNA-control group and the blank group ( $\mathrm{P}>0.05)$ (Fig. 4).

\section{Discussion}

It has been shown that current treatment of osteosarcoma by surgical operation and adjuvant chemotherapy cannot achieve satisfactory outcomes $(5,19,20)$. Multiple examples are given to demonstrate the potential positive role of gene therapy in the treatment of osteosarcoma $(7,21,22)$, indicating that the search of osteosarcoma target on genetic level may be of great significance for a better treatment of osteosarcoma. In this study, the effect of $D P T$ gene silencing on the apoptosis and proliferation of osteosarcoma MG-63 cells was studied, and the results may provide some insights for the development of new DPT-targeting inhibitors with clinical efficacy in the treatment of osteosarcoma.

Initially, in this study, $D P T$ gene silencing was found to reduce the proliferation of MG-63 cells. DPT is an acidic protein that promotes the formation of collagen fibril and reduces the diameter of newly formed collagen fibril $(23,24)$. It is reported that DPT in mammals may promote the adhesion of fibroblasts through an integrated receptor channel function as well as accelerating the synthesis of collagen fibrils (25). DPT binds to decorin, a small leucine-rich proteoglycan, which can be involved in tumor stroma formation, normal tissue development and differentiation (26). Besides, Decorin may mediate the function of proteins involved in extracellular-matrix formation $(27,28)$. Study conducted by Catherino et al also suggested that altered $D P T$ expression could interfere with decorin activity and cause abnormal extracellular-matrix formation (16). Furthermore, RNA interference, a well-known technique for silencing gene expression, can cause the inhibition of proliferation of tumor cells (29). We can therefore speculate that $D P T$ gene silencing could reduce the proliferation of MG-63 cells. The further mechanism should be further investigated.

Besides, in this study, it was also shown that DPT gene silencing can slow down the cell cycle progression and promote apoptosis. The ability of cell adhesion and invasion is the key to cancer metastasis, and as a proteoglycan binding to other proteins, $D P T$ can enhance the adhesion between fibroblasts and keratinocytes by accelerating the formation of collagen and fibronectin fibrils as well as by promoting the cell-matrix interaction $(13,30)$. When $D P T$ is active, it can improve wound healing by altering the extracellular environment; whereas when $D P T$ is not active, it cannot induce early osteogenesis (30-32), suggesting that cell regeneration is relatively slow when $D P T$ is inactive. $D P T$ is a downstream target of vitamin
$\mathrm{D}$ receptor during the differentiation of pluripotent stromal cells into osteoblasts and may function as growth factors, i.e., $D P T$ produced by tumor cells may up-regulate growth factor expression in stromal cells (18). Therefore, it can be deduced that $D P T$ silencing will reduce the expression of cell growth factors, thereby slowing the cell cycle progression. Apoptosis is an important mechanism to eliminate malignant cells and cancer cells can block the apoptotic pathway, thus avoiding apoptosis (33). Takeuchi et al (18) showed that DPT receptors are located in the tumor matrix of the rats and will promote the occurrence and progression of certain cancers, suggesting that $D P T$ is not conducive to apoptosis. Therefore, it can be postulated that $D P T$ silencing may reinstate the apoptosis mechanism and promote cell death.

In conclusion, shRNA plasmids that can effectively silence the expression of $D P T$ gene were successfully constructed in our study. The results showed that $D P T$ gene silencing could effectively reduce the proliferation of MG-63 cells, slow down the cell cycle progression and promote cell apoptosis. This provides some insights for the development of new inhibitors targeting DPT in the treatment of osteosarcoma. However, the discovery reported in this paper is still preliminary. Therefore, further studies are required to investigate the potential application of relevant drugs as well as their role in the prognosis of osteosarcoma.

\section{Acknowledgements}

The present study was supported by Guangxi Zhuang Autonomous Region Natural Science Foundation (grant no. 2014jjAA40654), The authors would like to acknowledge the helpful comments on this paper received from our reviewers.

\section{References}

1. Clark JC, Dass CR and Choong PF: A review of clinical and molecular prognostic factors in osteosarcoma. J Cancer Res Clin Oncol 134: 281-297, 2008.

2. Wu H, Li W, Zhang M, Zhu S, Zhang D and Wang X: Inhibitory roles of miR-320 in osteosarcoma via regulating E2F1. J Cancer Res Ther 12: 68-71, 2016.

3. Qureshi A, Ahmad Z, Azam M and Idrees R: Epidemiological data for common bone sarcomas. Asian Pac J Cancer Prev 11: 393-395, 2010.

4. Baldauf C, Jeschke A, Kanbach V, Catala-Lehnen P, Baumhoer D, Gerull H, Buhs S, Amling M, Nollau P, Harroch S and Schinke T: The protein tyrosine phosphatase Rptp广 suppresses osteosarcoma development in Trp53-heterozygous mice. PLoS One 10: e0137745, 2015.

5. Fromigué O, Haÿ E, Modrowski D, Bouvet S, Jacquel A, Auberger P and Marie PJ: RhoA GTPase inactivation by statins induces osteosarcoma cell apoptosis by inhibiting p42/p44-MAPKs-Bcl-2 signaling independently of BMP-2 and cell differentiation. Cell Death Differ 13: 1845-1856, 2006.

6. Kansara M, Teng MW, Smyth MJ and Thomas DM: Translational biology of osteosarcoma. Nat Rev Cancer 14: 722-735, 2014.

7. Kansara M, Tsang M, Kodjabachian L, Sims NA, Trivett MK, Ehrich M, Dobrovic A, Slavin J, Choong PF, Simmons PJ, et al: Wnt inhibitory factor 1 is epigenetically silenced in human osteosarcoma, and targeted disruption accelerates osteosarcomagenesis in mice. J Clin Invest 119: 837-851, 2009.

8. Kuijjer ML, Rydbeck H, Kresse SH, Buddingh EP, Lid AB, Roelofs $\mathrm{H}$, Bürger $\mathrm{H}$, Myklebost $\mathrm{O}$, Hogendoorn $\mathrm{PC}$, Meza-Zepeda LA and Cleton-Jansen AM: Identification of osteosarcoma driver genes by integrative analysis of copy number and gene expression data. Genes Chromosomes Cancer 51: 696-706, 2012. 
9. Sadikovic B, Yoshimoto M, Chilton-MacNeill S, Thorner P, Squire JA and Zielenska M: Identification of interactive networks of gene expression associated with osteosarcoma oncogenesis by integrated molecular profiling. Hum Mol Genet 18: 1962-1975, 2009.

10. Okamoto O, Hozumi K, Katagiri F, Takahashi N, Sumiyoshi H, Matsuo N, Yoshioka H, Nomizu M and Fujiwara S: Dermatopontin promotes epidermal keratinocyte adhesion via alpha3betal integrin and a proteoglycan receptor. Biochemistry 49: 147-155, 2010.

11. Mark way BD, Cho H, Anderson DE, Holden P, Ravi V, Little CB and Johnstone B: Reoxygenation enhances tumour necrosis factor alpha-induced degradation of the extracellular matrix produced by chondrogenic cells. Eur Cell Mater 31: 425-439, 2016.

12. Lu H, Liu S, Zhang G, Kwong LN, Zhu Y, Miller JP, Hu Y, Zhong W, Zeng J, Wu L, et al: Oncogenic BRAF-mediated melanoma cell invasion. Cell Rep 15: 2012-2024, 2016.

13. Yamatoji M, Kasamatsu A, Kouzu Y, Koike H, Sakamoto Y, Ogawara K, Shiiba M, Tanzawa H and Uzawa K: Dermatopontin: A potential predictor for metastasis of human oral cancer. Int J Cancer 130: 2903-2911, 2012.

14. Fu Y, Feng MX, Yu J, Ma MZ, Liu XJ, Li J, Yang XM, Wang YH, Zhang YL, Ao JP, et al: DNA methylation-mediated silencing of matricellular protein dermatopontin promotes hepatocellular carcinoma metastasis by $\alpha 3 \beta 1$ integrin-Rho GTPase signaling. Oncotarget 5: 6701-6715, 2014.

15. Kuroda K, Okamoto O and Shinkai H: Dermatopontin expression is decreased in hypertrophic scar and systemic sclerosis skin fibroblasts and is regulated by transforming growth factor-beta1, interleukin-4, and matrix collagen. J Invest Dermatol 112: 706-710, 1999.

16. Catherino WH, Leppert PC, Stenmark MH, Payson M, Potlog-Nahari C, Nieman LK and Segars JH: Reduced dermatopontin expression is a molecular link between uterine leiomyomas and keloids. Genes Chromosomes Cancer 40: 204-217, 2004.

17. Russell SB, Russell JD, Trupin KM, Gayden AE, Opalenik SR Nanney LB, Broquist AH, Raju L and Williams SM: Epigenetically altered wound healing in keloid fibroblasts. J Invest Dermatol 130: 2489-2496, 2010.

18. Takeuchi T, Suzuki M, Kumagai J, Kamijo T, Sakai M and Kitamura T: Extracellular matrix dermatopontin modulates prostate cell growth in vivo. J Endocrinol 190: 351-361, 2006.

19. Bacci G, Bertoni F, Longhi A, Ferrari S, Forni C, Biagini R, Bacchini P, Donati D, Manfrini M, Bernini G and Lari S: Neoadjuvant chemotherapy for high-grade central osteosarcoma of the extremity. Histologic response to preoperative chemotherapy correlates with histologic subtype of the tumor. Cancer 97: 3068-3075, 2003

20. Allison DC, Carney SC, Ahlmann ER, Hendifar A, Chawla S Fedenko A, Angeles C and Menendez LR: A meta-analysis of osteosarcoma outcomes in the modern medical era. Sarcoma 2012: $704872,2012$.
21. Xin M, Qiao Z, Li J, Liu J, Song S, Zhao X, Miao P, Tang T, Wang L, Liu W, et al: miR-22 inhibits tumor growth and metastasis by targeting ATP citrate lyase: Evidence in osteosarcoma, prostate cancer, cervical cancer and lung cancer. Oncotarget 7: 44252-44265, 2016.

22. Cheng S, Zhang X, Huang N, Qiu Q, Jin Y and Jiang D: Down-regulation of S100A9 inhibits osteosarcoma cell growth through inactivating MAPK and $\mathrm{NF}-\kappa \mathrm{B}$ signaling pathways. BMC Cancer 16: 253, 2016

23. Neame PJ, Choi HU and Rosenberg LC: The isolation and primary structure of a $22-\mathrm{kDa}$ extracellular matrix protein from bovine skin. J Biol Chem 264: 5474-5479, 1989.

24. Tracy LE, Minasian RA and Caterson EJ: Extracellular matrix and dermal fibroblast function in the healing wound. Adv Wound Care (New Rochelle) 5: 119-136, 2016

25. Kato A, Okamoto O, Ishikawa K, Sumiyoshi H, Matsuo N, Yoshioka H, Nomizu M, Shimada $T$ and Fujiwara S: Dermatopontin interacts with fibronectin, promotes fibronectin fibril formation, and enhances cell adhesion. J Biol Chem 286 14861-14869, 2011.

26. Riquelme C, Larrain J, Schonherr E, Henriquez JP, Kresse H and Brandan E: Antisense inhibition of decorin expression in myoblasts decreases cell responsiveness to transforming growth factor beta and accelerates skeletal muscle differentiation. J Biol Chem 276: 3589-3596, 2001.

27. Dudás J, Kovalszky I, Gallai M, Nagy JO, Schaff Z, Knittel T, Mehde M, Neubauer K, Szalay F and Ramadori G: Expression of decorin, transforming growth factor-beta 1, tissue inhibitor metalloproteinase 1 and 2, and type IV collagenases in chronic hepatitis. Am J Clin Pathol 115: 725-735, 2001.

28. Costacurta A, Priante G, D'Angelo A, Chieco-Bianchi L and Cantaro S: Decorin transfection in human mesangial cells downregulates genes playing a role in the progression of fibrosis. J Clin Lab Anal 16: 178-186, 2002.

29. Zhang S, Yang JH, Guo CK and Cai PC: Gene silencing of TKTL1 by RNAi inhibits cell proliferation in human hepatoma cells. Cancer Lett 253: 108-114, 2007.

30. Krishnaswamy VR and Korrapati PS: Role of dermatopontin in re-epithelialization: Implications on keratinocyte migration and proliferation. Sci Rep 4: 7385, 2014.

31. Kato A, Okamoto O, Wu W, Matsuo N, Kumai J, Yamada Y, Katagiri F, Nomizu M and Fujiwara S: Identification of fibronectin binding sites in dermatopontin and their biological function. J Dermatol Sci 76: 51-59, 2014.

32. Behnam K, Murray SS and Brochmann EJ: BMP stimulation of alkaline phosphatase activity in pluripotent mouse $\mathrm{C} 2 \mathrm{C} 12$ cells is inhibited by dermatopontin, one of the most abundant low molecular weight proteins in demineralized bone matrix. Connect Tissue Res 47: 271-277, 2006.

33. Fernald K and Kurokawa M: Evading apoptosis in cancer. Trends Cell Biol 23: 620-633, 2013. 